\title{
Considering the Importance of User Profiles in Interface Design
}

\author{
Yuanhua Liu, Anna-Lisa Osvalder and MariAnne Karlsson \\ Division Design \& Human Factors \\ Department of Product \& Production Development \\ Chalmers University of Technology \\ Sweden
}

\section{Background}

Human-computer interaction (HCI) is an interdisciplinary research area which concerns the study of interaction between humans (operators as users) and computers. A widely used definition interprets this concept as "a discipline concerned with the design, evaluation and implementation of interactive computing systems for human use and with the study of major phenomena surrounding them" (ACM SIGCHI, 1992). The reason for stating 'interdisciplinary' as the nature of $\mathrm{HCI}$ is the involvement of different disciplines contributing to HCI. Computer science is not the only discipline contributing to HCI; other disciplines, such as cognitive psychology, human factors, engineering, design, social and organizational psychology are also considered important and relevant.

In the past for many years, a comprehensive range of research and studies concerning different aspects of HCI has been conducted or implemented. These studies are diverse, and include, for instance, dialogue techniques, gestural analysis and multimodal interfaces, computer graphics, computational linguistics, spatial cognition, robot navigation and wayfinding, input styles or devices, and monitor screens etc. However, the ultimate goal of the studies is to contribute to improving the interaction between humans and computer systems by endowing technical systems with higher usability and satisfaction.

Facilitating the mutual interaction by presenting information on the status of the computer systems, a user interface normally works as a kind of communication platform or bridge between human beings and computers during the interaction. However, humans work as users operating or controlling the system by processing and interpreting the information. How to design interfaces that assist users in task performance in an optimal manner during interactions is a major challenge for all design engineers. When users interact with computer systems, many factors can influence overall performance. These factors cover various issues from the user side, task side, technical system side, and working environment/context side. Recently, from the perspective of human factors engineering, Osvalder \& Ulfvengren (2009) have proposed performance-shaping factors (PSFs) as a generic name for those different influential factors. Furthermore, they have classified the PSFs into three categories: internal factors, external factors and stressors. The internal factors refer to physical and mental conditions that are either inbuilt or brought by humans as operators, such as age, vision, 
personality and motivation etc. The external factors refer to latent and operational issues relevant to working environment and work contexts, such as surrounding environment, shift rotation, equipment \& tools, work procedure and operator interfaces etc. Stressors are mostly those psychological or physiological pressures affecting the operator's decisionmaking and action either directly or indirectly, such as high workload, high work pace, pain, exhaustion, long-term stress etc. These performance-shaping factors affect the operator's performance either individually or in combination. The purpose of summarizing and studying different influential factors is to provide useful implications for computer engineers in order to optimize interaction design.

Consequently, a number of different design methodologies addressing techniques for $\mathrm{HCI}$ design have emerged in recent years. The rationale of most design methodologies is based on a model illustrating how user, designer and technical systems interact. In the early years, users' cognitive processes were regarded as important predictable issues in many design methodologies. Nowadays, good and efficient communication between users and designers is viewed as a focus in modern design philosophies, thus urging technical systems to cover the type of experiences users want to have. User-centered design (UCD) is a very popular design philosophy aiming to put users at center-stage in the design processes of technical systems, as well as to give end users' requirements and limitations extensive attention at each stage of the design process. User requirements are considered and treated as a focus in the whole product life cycle. The typical characteristics of the UCD design philosophy are end users' active participation in the design process and an iteration of design solutions. Therefore, designers should not only analyze or foresee how users interact with an interface, but also test the validity of their assumptions concerning users' behaviour in real- world tests with real users. Compared to other interface design philosophies, UCD focuses on optimizing the user interface around how users can, want, or need to work, rather than forcing the users to change their mental models or behaviour to accommodate the designers' approach. In order to achieve this design hypothesis, users, designers and technical practitioners work together to articulate the wants, needs and limitations of the user and create a technical system that meets these requirements.

The basic idea of the UCD philosophy is to emphasize good understanding of the user so as to develop more usable artifacts. Needs diversity involves accommodating users with expertise difference, knowledge difference, age difference, gender difference, and cultural difference etc. (Schneiderman, 2000). In order to understand the users and their needs, user analysis becomes a critical aspect of UCD process. User analysis often means distinguishing users broadly in terms of age, gender, expertise with technology, educational background, attitude toward the technology, linguistic ability etc.

\section{Users in the $\mathrm{HCl}$}

Describing users and work tasks is critical for studies of the HCI system. In the common sense, users are normally characterized as the class of people who use a technical system and might not necessarily have complete technical expertise with the system. For quite a long time, the user concept has become blurred by different schools of thought. Users are defined differently in different theories: as components of a system in 'Distributed cognition theory', as problem solvers in 'Information processing theory', as resourceful individuals in 'Situated actions theory', as human actors in 'Activity theory', and so on. However, from a practical perspective, the definition of users is always based on their relation to products or 
artefacts. Karlsson (1996) indicated that the definition of users should be associated with the use-activity, i.e. the type of human-artifact relation. Thus, the user is defined as the end user, i.e. "the human being engaged in a use activity" (Karlsson, 1996). Warell (2001) defined a user as "any individual who, for a certain purpose, interacts with the product or any realised element (system, part, component, module, feature, etc., manifested in software or as concrete objects) of the product, at any phase of the product life cycle." This definition is more comprehensive and practical from the perspective of product design and development, since humans' interaction with the product in the whole product life cycle is taken into consideration.

Users may be classified in different respects. For instance, many researchers classify users according to users' relation to the products or other users. Monö (1974) classified users into target groups and filter groups. According to Monö (1974), users in the target groups are the persons for whom the product is developed or design, while the users in the filter groups may be distributors or purchasers who may influence the target groups' choice of product. Buur \& Windum (1994) classified users into two categories - primary users and secondary users. Primary users are those who use the product for its primary purpose, e.g. dialysis nurses who handle a dialysis machine in a medical treatment, while secondary users are those who actively use the product but not for what is primarily intended, e.g. maintenance personnel. Based on Buur \& Windum's (1994) classification, Janhager (2003) added two other user categories: side-users and co-users. Side-users are "people who are affected by the product, either negatively or positively, in their daily life but without using the product", e.g. patients receiving ventilation treatment, while co-users are "people who co-operate with a primary or secondary user in some way without using the same product", e.g. medical doctors.

However, in HCI, users' individual differences and their tasks are always indicated as the two most important issues addressing usability (Nielsen, 1993). Users are not homogeneous; they differ in many respects, such as gender, age, physical abilities, educational level, organizational culture, operator skills etc. It is the diversities that make users both different from each other as individuals and similar as a collective group. The importance of user characteristics, e.g. age, gender, body dimensions and training, is always stressed, since user characteristics can influence the use situation and thus have an impact on the product design (Hedge, 1998; Preece, 2002). Considering that user characteristics define the users' abilities and limitations in the use situation, many researchers have classified users on the basis of user characteristics and carried out studies to investigate how these characteristics influence users' performance in the interaction with technical systems. For instance, elderly users were found to have a decline in higher-order cognitive processes, such as attention (Owsley et al., 1991), and also a slower speed in almost all tasks that stress rapid performance (Botwinick, 1973; Welford, 1977). Broos (2005) carried out a study on gender aspects and found that women showed a higher computer anxiety than men, implying that men are more self-assured and women are more hesitant.

The purpose of user classifications is to identify or investigate users and their performance or acceptance of product design, thus providing useful information or a basis to designers for product improvement. Faulkner (2000) and Preece (2002) stressed the importance of considering users' use experience of the product. Engelbrektsson (2004) identified three different types of use experience that result in different enabling effects in user elicitation: "problem experience enabling through the users having e.g. experienced problems with existing product design; interaction experience enabling through the users gaining 
experience of interacting with a user interface and becoming aware of the properties of the product; and product use experience enabling through the users gaining experience of using the product in a use activity, i.e. a situation in which the product has become a mediator in order to reach the user's goal." However, considering users' use experience of the product from perspectives of product evaluation and interaction, use experience here is classified as interaction experience and use experience. Interaction experience addresses how users gain experience of the product by interacting with a user interface in a specific or certain situation, e.g. usability tests. Use experience refers to the experience that users gain by using the product in real life.

Janhager (2005) indicated that length of use and education concerning the product, and frequency of use, are the two bases for defining users' use experience of the product. However, apart from length of use and frequency of use, users' expertise level is a most direct and precise criterion for determining users' use experience of the product.

\section{User profiles}

As a popular term widely used by industrial companies to represent real users, the user profile is a method of presenting data from studies of user characteristics (Janhager, 2005). It may also be supplemented with a description of relationships between various users. Kuniavsky (2003) indicated that the 'user profile' is almost the same as a persona, i.e. some kind of fictitious person as a collection of attributes (e.g. goals, age, attitudes, work, and skills). In other words, a user profile of the target group contains collective information about mental, physical and demographic data for the user population as well as other characteristics. It is possible to make user profiles for one or more fictional individual users in the form of personas, thus describing the user's characteristics in the form of knowledge, abilities and limitations in relation to the product, equipment or system with which the user will be integrating (Osvalder et al., 2009). The ultimate purpose of using user profiles or persona is actually to help designers to recognize or learn about the real user by presenting them with a description of a real user's attributes, for instance; the user's gender, age, educational level, attitude, technical needs and skill level. User profile does not necessarily mirror or present a complete collection of a whole user population's attributes. The essence of user profiles is accurate and simple collection of users' attributes. In the product design process, user profiles are normally created early and used as a basis for usability evaluation and product redesign.

\subsection{Age difference}

Age is an important issue to bear in mind. Aging has been found to result in a decline in, for instance, the physiology and neurophysiology of the eye (Darin, et al., 2000); in physical, sensory and cognitive factors (Craik \& Salthous, 2000; Hitchcock et al., 2001; Scialfa et al., 2004); in higher-order cognitive processes; such as attention (Owsley, et al., 1991), and in a slower speed in almost all tasks that stress rapid performance (Botwinick, 1973; Welford, 1977). It is generally accepted that, such declines accelerate after individuals reach their midforties (Hawthorn, 2000). At the same time older individuals have been argued to become more cautious (Okun \& Di Vesta, 1976), and therefore more prone to plan before acting, rather than applying a trial-and-error approach. In computer-based work, it was found that older people took longer time and made more errors (Czaja \& Sharit, 1993; Laberge \& 
Scialfa, 2005; Sayer, 2004), as well as showed slower in performance and made more slips in using input devices (Chaparro et al., 1999; Smith et al., 1999).

Kang and Yoon (2008) made a study comparing the behaviour of younger and middle-aged adults when interacting with complicated electronic devices. Their results revealed that age differences meaningfully affected the observed error frequency, the number of interaction steps, the rigidity of exploration, the success of physical operation methods, and subjective perception of temporal demand and performance. In contrast, trial-and-error behaviour and frustration levels were influenced by background knowledge rather than age.

Elderly people were also found to have more usability problems in the use of mobile phones (Ziefle \& Bay, 2005). When investigating elderly people's use of mobile phones and characteristics of an aging-friendly mobile phone, Kurniawan (2008) found that elderly people experience fear of consequences of using unfamiliar technology.

\subsection{Gender difference}

The significance of considering, for instance, gender has been shown by Belenky et al. (1986), Philbin et al. (1995), as well as by Sadler-Smith (1999). These studies propose; e.g. that males tend to be more abstract learners, more intuitive and undirected, while females are more anxious about results, more analytical and organized. Furthermore, Barret and Lally (1999) conclude that males behaved more actively than females in a formal on-line learning environment, e.g. sending more and longer messages. In a recent study by Broos (2005), it was found that females showed a higher computer anxiety than males, implying that males are more self-assured and females are more hesitant. Gender differences are also found in preferred design features, for instance, females focusing on haptic aids and males on perceptual aids (Kurniawan, 2008).

\subsection{Cultural difference}

Cross-cultural design of interfaces is currently pervasive in industries and manufacturing. Such a trend brings up research concerning the validity of cross-cultural design, the impact of cultural differences on users' behaviour in interaction, as well as how to incorporate and accommodate cultural differences in interface design etc. Human beings are always thought of as having similar basic psychological characteristics, i.e. humans across the world perceive and reason in the same way (Brown, 1991; Pinker, 2006). Segall et al., (1999) pointed out that cultural differences influence humans' application of preferred skills and strategies to cognitive processes in each particular situation, even though humans share similar basic cognitive functions. As compelling evidence shows, how people from different demographic regions in the world perceive objects and situations is shaped by cultural-historical differences in physical environment, upbringing, education and social structure (Nisbett, 2003; Nisbett et al., 2001).

Linking to usability evaluation methodology, cultural issues are always excluded from the influential factors group and conceived as non-influential on outcomes of usability evaluation in most studies (Clemmensen et al., 2009). For many years, studies have been made to investigate the effect of influential factors on the outcomes of usability evaluation, such as choice of task scenarios, number of test participants, choice of methodologies, choice of test places etc. However, less attention is given to cultural effects on the evaluation process, for instance, whether or how test participants' cultural background affects evaluation outcomes, and whether choice of task scenarios and interface heuristics should 
overlook cultural effects. Concerning disagreements between usability studies, discussions are rarely conducted in terms of cultural effects.

Clemmensen et al. (2009) made a deep analysis of cultural cognition in usability evaluation and illustrated the impact of cultural cognition on four central elements of the thinkingaloud method (TA): (1) instructions and tasks; (2) the user's verbalizations; (3) the evaluator's reading of the user, and (4) the overall relationship between user and evaluator. In conclusion, some important findings are emphasized, such as the importance of matching the task presentation to users' cultural background, the different effects of thinking aloud on task performance between Easterners and Westerners, the differences in nonverbal behaviour that affect usability problem detection, and the complexity of the overall relationship between a user and an evaluator with different cultural backgrounds.

\subsection{User expertise}

In the literature, 'expertise' is defined as the mechanism underlying the superior achievement of an expert, i.e. "one who has acquired special skill in or knowledge of a particular subject through professional training and practical experience" (Webster's Dictionary, 1976), or "expert knowledge or skill, especially in a particular field" (Oxford Advanced Learner's Dictionary, 1995). However, what we always mean by 'users' expertise' is users' special skill or knowledge that is acquired by training study, or practice. It is obvious that users' expertise is related to their practice or experience with a specific system or subject, and can be seen as a consequence of the users' capacity for extensive adaptation to physical and social environments.

Users' experience with a specific system or subject is the dimension that is normally referred to when discussing user expertise (Nielsen, 1993). As a matter of fact, differences in users' experience are a practical issue in human-machine interaction (HMI) or human-computer interaction (HCI). The development of users' expertise often comes about through long periods of deliberate practice. To a certain extent, users' experience with a specific system or subject can greatly facilitate their acquisition of expertise. In many studies, users are classified into different categories according to the users' different experience. For instance, Shneiderman (1992) indicated three common classes of users along the user experience scale: (1) novice users - " users who know the task but have little or no knowledge of the system"; (2) knowledgeable intermittent users - "users who know the task but because of infrequent use may have difficulty remembering the syntactic knowledge of how to carry out their goals"; and (3) expert frequent users - "users who have deep knowledge of tasks and related goals, and the actions required to accomplish the goals". Nielsen's (1993) classification is similar to Shneiderman's (1992), i.e. users can be classified as either novices or experts, or somewhere in -between. Comparisons between novice and expert users can never be overlooked when studying users' differences in expertise. Although theoretical definitions of the users' expertise categories (i.e. novice user, intermittent user, and expert user) are provided by some researchers, such as Shneiderman (1992) and Nielsen (1993), the boundaries between the user categories are actually very vague. One reason is that novice users will evolve into expert users after sometime learning and practice. The development of expertise is a learning process with progressive acquisition of skill between novices and experts. This implies that users' expertise categories are dynamic and status-based. Users' acquisition of skill is normally proportional to time and practice. However, it is almost impossible to distinguish the user categories by means of exact date/time or exact amount of practice. The categorization can only be based on the immediate status of the users' skill level. 
A common idea is that experts appear to have fewer errors and lower severity of errors than novices in performance (Larkin, 1983). In addition, experts' mental models are more abstract and novices' models appear more concrete concerning levels of knowledge (DiSessa, 1983; Doane, 1986; Greeno, 1983; Larkin, 1983). Expert users have been argued to be better at detecting design defaults (Dreyfus \& Dreyfus, 1986), understanding functional relationships (Chi et al., 1981), and identifying problem-solving strategies (Klein, 1999). The simple differences between novices and experts can also be found in some objective measures of performance, such as error rates during task completion, time expenditure during task completion, problem-solving, decision-making and judgment. Such distinctions can be seen in many fields. For example, expert programmers can always write computer programs in a more concise and logical way than novice programmers; expert medical physicians are almost always better at diagnosing a disease correctly than novice physicians; expert pilots are generally more skilful at judging the situation precisely and coping with occasional events than novice pilots.

\section{User expertise vs. mental models}

In $\mathrm{HCI}$, mental models are frequently mentioned in interface design and tied closely to usability; this is because of their major role in cognition and decision-making during the process of interaction. With the help of mental models, designers can get a clear picture of what users are trying to accomplish, and then align design strategy with users' behaviour accordingly and effectively. Mental models are always indicated as psychological or inner representations of reality that people use to understand specific phenomena. The concept of 'mental model' was first formulated by Kenneth Craik (1943) with an assumption that people rely on mental models in their performance. A mental model reflects the true roots of human behaviour, philosophies and emotion about how to accomplish tasks. In the light of Johnson-Laird's (1983) definition, mental models reveal the process in which humans handle and tackle tasks of deductive reasoning, and they might not necessarily be more complex or represent real-life cases. Sasse (1997) pointed out that many existing mental model theories are supported by the following assumptions: (1) users form a mental model of the internal workings of the computer systems they are interacting with; (2) the content and structure of that mental model influence how users interact with a system; (3) selecting what information about the system is presented to users and how it is presented can influence the content and structure of a mental model; (4) more detailed knowledge of how users construct, invoke, and adapt mental models could be used to provide guidance for user interfaces and user training, which could help users to form appropriate models. A common view, from the existing theories of mental models, is that humans can build up mental models by perception, imagination or conversation. Many researchers are devoted to investigating how mental models are constructed. However, there is no agreement on exactly how mental models are constructed. Some issues of disagreement are found between different theories, such as the structure of the mental models how the mental models influence the interaction between the user and the system, and how the mental models are constructed (Sasse, 1997). Burns (2000) indicated that mental models traditionally have been characterised in two ways, i.e. the construction of a mental model in a specific situation, and as being activated from generalised knowledge. Mental models can be incomplete, simple, abstract and even general. They can also be continuously evolving. The more detailed and correct the mental models are, the more success users will achieve when interacting with machines or devices. 
Mental model issues are important and helpful to comprehend how humans process information in various environments. It has long been assumed that users do employ some type of model when interacting with machines. Norman (1983) indicated that mental models provide 'predictive and explanatory power' for understanding the interaction. Norman (1983) indicated the designer's mental model as a conceptual model. A few years later, Norman (1986) proposed a diagram and distinguished designers' models (i.e. the design model) and users' mental models (i.e. the user's model). Designers' models are always assumed to be an accurate, consistent and complete representation of the target system, whereas users' models might be limited and partial mental models of the designers' models. On condition that a user's mental model matches a designer's model, usability can be achieved and errors can be reduced.

Many studies have been made to investigate whether users actually have and use mental models when interacting with devices and systems (Rogers et al., 1992). By observing users' performance on a system and comparing novice-expert differences in problem-solving abilities within a particular domain, most of the research infers the existence of mental models. Users' mental model will affect the success of their performance. Reason (1990) stated that inaccurate mental models of more complex systems (e.g. airplanes, nuclear reactors) can lead to disastrous accidents. Burns (2000) indicated that decision errors are not actual errors but normal consequences of the operator's mental model.

Referring to the user expertise issue, a relevant question is whether novice and expert users have the same or different mental models during the interaction, and how their mental models facilitate their performance. Larkin (1983) investigated how novices and experts reason about a physical situation, and found that the novice's model represents objects in the world and simulates processes occurring in real time, whereas the expert's model represents highly abstract relations and properties. A common idea of many researchers is that experts' mental models are more abstract and novices' models appear more concrete concerning levels of knowledge (DiSessa, 1983; Doane, 1986; Greeno, 1983; Larkin, 1983). DiSessa (1983) used the term 'macro-model' to describe experts' richer and more abstract models. Experts appear to have fewer errors and lower severity of errors than novices in performance (Larkin, 1983). Concerning problem-solving abilities, novices were paralyzed by their ability to solve problems, while experts had several strategies for problem-solving (Stagger \& Norcio, 1993). In a study on computer programming, for instance, Davies (1994) found that expert problem- solvers extracted additional knowledge from their more complex mental models to solve the tasks, while novice problem-solvers focused on the surface features of a problem. Novices reason on the basis of mental simulations that call for the construction of models representing typical sequences of affairs (Kahneman \& Tversky, 1982). However, there are still many related issues that are unclear or not solved yet - for instance, when interacting with an unknown or new system/device, how much help expert users can get from their existing mental models to construct new mental models, and whether expert and novice users have different mental models when they navigate the unknown system/device, neglecting the complex levels of interfaces. Furthermore, whether expert users' old mental model can adapt to a new interaction context, how such adaptation facilitates or affects their interaction performance in the new context, and what external factors can bring disturbance to the adaptation, are of great concern to researchers.

The different types or brands of a machine/system can either resemble or differ from each other in some aspects of interface; for instance, in terms of icons, symbols, layout of information display, menus, and terminology. The resemblance between similar 
machines/systems can lead to confusion for users in the interaction, due to a lack of firm boundaries between mental models (Norman, 1983). Although the basic underlying theory of machine handling is more or less the same, there are two typical theoretical views produced to illustrate how expert users' mental models facilitate their performance in navigation during interactions. The difference between the two theoretical views is whether or not expert users depend on the organization of the interface in their interaction. For instance, Spiro et al. (1988; 1991) proposed the Cognitive Flexibility Theory (CFT) to emphasize the adaptation of expert users' mental models to the new and unknown interface, implying that expert users outperform novice users due to their mental model's adaptation to match the changes of the new or unknown interface/system. However, Vicente and Wang's (1998) Constraint Attunement Hypothesis (CAH) theory indicates that expert users' better performance is tied to the organization of the interface, implying that expert users will outperform novice users if the new and unknown interface resembles the old interfaces. In reality, such resemblance and variation in interface organizations are unpredictable and controlled by manufacturers. Based upon systematic research on users' expertise in different interaction situations, it was found that expert users appear to rely on their latest mental model in problem solving when novice and expert users interact with a new and unknown type or brand of a simple machine/system (Liu, 2009). This implies that expert users tend to rely on their old mental models to explore a new and unknown interface. When facing new terminologies in the interaction, expert users' efforts to solve the problem appeared to be based on semantic resemblance, while the novice users' efforts appeared to be purposeless (Liu, 2009). What could be learned from the findings of this current research is that expert users' navigations are based on their old mental models when interacting with a new and unknown interface. Novice users chance to explore or navigate the interface without any existing old mental models. In addition, Liu (2009) indicated the two sides of expert users' old mental models, i.e. the existing old mental models can both benefit and impede expert users' interaction with a new or unknown interface. The positive and negative roles of experts' old mental models depend on the amount of resemblance or difference between the old and the new/ unknown interfaces.

On the one hand, expert users could benefit in their interaction when their old mental models comply with the design of the new interface. On the other hand, when expert users' old mental models do not comply with the new design, expert users may have problems in their interaction or confront failures in exploration if they stick too firmly to their old mental models. In order to avoid this negative effect, it is important for designers and manufacturers to consider standardization issues in design. Liu and Osvalder (2009) pointed out that terminology was a serious problem when using the same medical devices from different manufacturers. Such terminology problems can cause confusion to expert users in their guessing and exploration, which influenced expert users' performance in the interactions. In real medical contexts, it is common to see that the same devices designed and produced by different manufacturers are used in the same units at hospitals. If there is a big difference in terminology between the same devices of different brands or types, then the terminology problem will bring unnecessary annoyance and stress to the medical staff, and it might even lead to potential risks in their routine work.

\section{Model of users' expertise vs. complexity of medical user interfaces}

The effect of users' expertise difference on users' performance in the interaction should be studied together with considering complexity of the interfaces. Until now, there has been no 
definite or widely accepted guideline or principle regarding how to classify or define the complexity of user interfaces. There could be different ways to classify the complexity levels of different interfaces. From a practical viewpoint, Liu (2009) proposed a way to define the complex levels of user interfaces based on five criteria: (1) ease of manipulation, which can be seen from learning and training; (2) hierarchy of tasks both in broadness and in depth; (3) amount of information in menu or pop-up windows; (4) number of items in menu and popup windows; and (5) amount of cognitive resources and physical resources required in the operation. Such a way of categorization is mainly based on amount of functions and subfunctions, hierarchical levels of menu systems, and training time. The rationale of the categorization has been successfully used in classifying medical user interfaces in medical fields which require higher and stricter safety at work. This could be seen in research on the relationship between differences in users' expertise and in the complexity of medical user interfaces (Liu et al., 2007; Liu, 2009). Concerning the effect of users' expertise on their

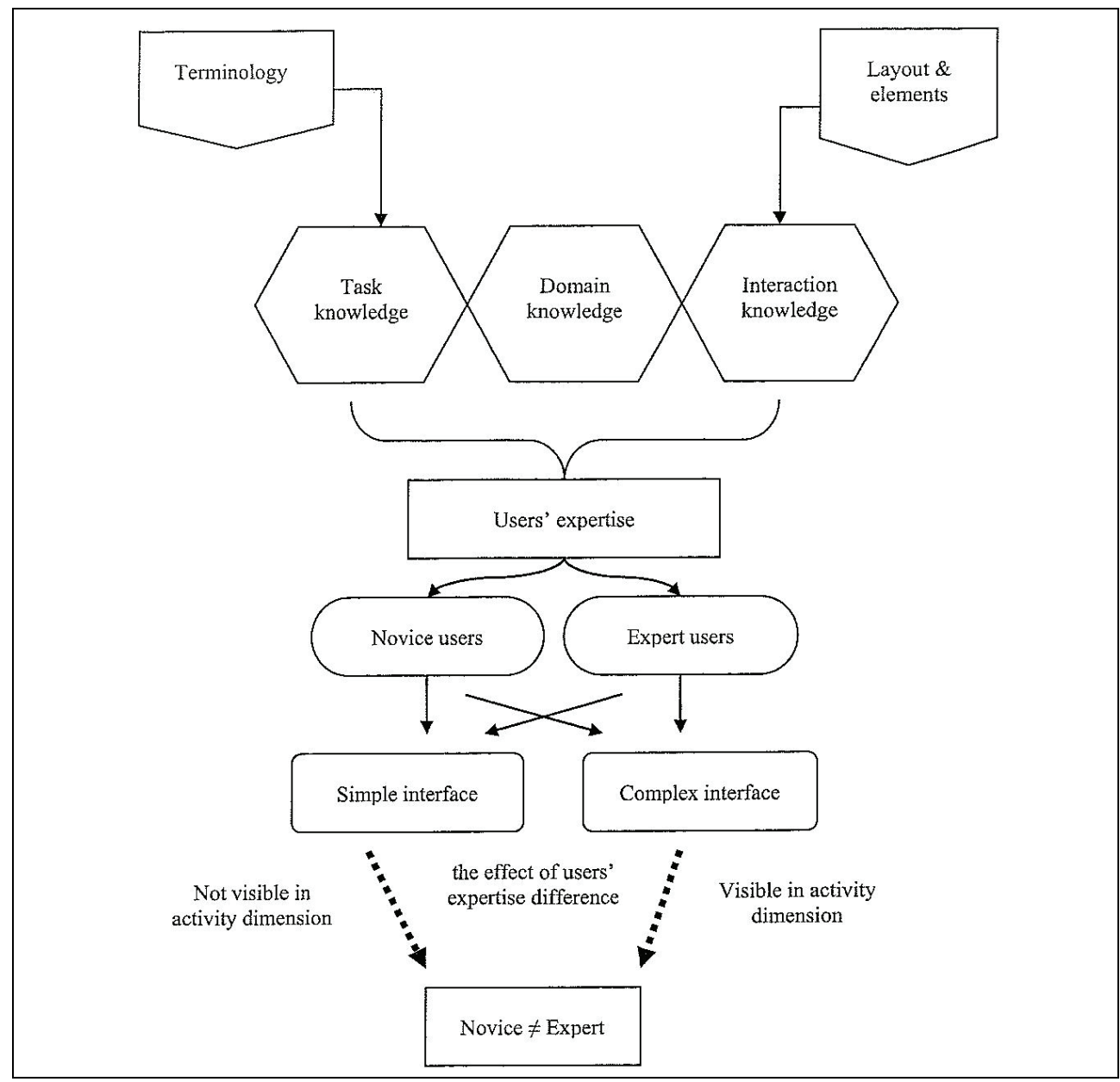

Fig. 1. Model of users' expertise vs. complexity of medical user interfaces 
interaction with medical devices, Liu (2009) proposed a model (Fig.1) illustrating users' expertise vs. complexity of medical user interfaces.

In the model, Nielsen's 'User cube' (1993) was adopted as the basis to analyze and classify users' expertise. The three dimensions that user expertise is classified along are interpreted as: (1) Interaction knowledge, i.e. the general knowledge about interacting with a specific machine interface and the relevant elements (e.g., recognizing the function of the menu system, layout and elements of the interface, buttons, icons, etc.); (2) Task knowledge, i.e. the knowledge of the task domain addressed by a specific interface/system (e.g., terminology); and (3) Domain knowledge, i.e. the theoretical knowledge or underlying theory about a task completion that is independent of a specific product or system (e.g., knowledge of how to act in order to cope with a certain state or task). For user(medical)device interaction in the medical field, the three dimensions along which user expertise is classified are interpreted correspondingly as: interaction knowledge about a specific medical device, task knowledge addressed by a specific medical device, and domain knowledge about the specific medical treatment. Thereby, expert users are defined as users who have rich interaction knowledge, task knowledge and domain knowledge of a specific system, and are skilful in obtaining and using the knowledge to achieve goals or tasks in the interaction. Likewise, novice users are defined as users who are naïve about a specific system, having less use/interaction experience, and appearing unskilful in using and obtaining knowledge to achieve goals and tasks in the interaction.

One issue illustrated by this model is the relationship between the interface and different components or dimensions of users' expertise. An obvious attribute of interfaces affecting the users' task knowledge is the terminology used (i.e. names of functions, concepts or icons). However, the obvious attributes of interfaces affecting the users' interaction knowledge appear to be layout and elements (e.g. menu structure and ways of interaction). Secondly, the model shows that the influence of users' expertise on users' behaviour differs in relation to the complexity levels of medical user interfaces. Such a model provides information about differences between novice and expert users in the activity dimension. When interacting with a simple medical user interface, the expert users are not superior to the novice users in performance. In other words, expert users appear similar to novice users in terms of task completion. However, the expert users outperformed the novice users when interacting with a complex medical user interface, implying that the effect of users' expertise difference is visible in the activity dimension. The complexity of complex user interfaces makes it easier for novice users to get lost in the navigation. Liu (2009) indicated that novice users appear to choose buttons or actions more or less by chance during the navigation, while expert users base their interaction on reasoning and decision-making reflecting their professional skill. Although this model was developed on the basis of usability studies in the medical area, the results and findings can be referred to or applied in other areas as well, such as process industries which demand high safety and high levels of users' expertise/skill.

\section{Impact of user expertise on usability evaluation}

\subsection{Users' expertise issue in usability evaluation}

Usability evaluation is an important step in design development and refinement for UCD and interactive design. For interface design, usability evaluation is needed in various stages of the whole design process, aiming to avoiding usability problems from the beginning. 
Usability testing (e.g., Nielsen, 1993; McClelland, 1995) is a commonly used method for assessing the usability of a product or system. A range of earlier studies has investigated the effects of different methodological approaches on the result of a usability test. For instance, different data collection methods have been compared including comparisons between theoretical and empirical evaluations (e.g. Karat, 1988; Landauer, 1988). Usability tests in laboratory environments have been contrasted to tests in real-life settings (e.g. Jørgensen, 1989). The effect of the number of subjects in the usability tests has been explored (e.g. Lewis, 1994; Virzi, 1992), and the outcome of individual versus cooperating users as test subjects has been investigated (Hackman \& Biers, 1992). Also the choice of evaluation tasks has been evaluated (Held \& Biers, 1992; Karat et al., 1992). Furthermore, the level of experimenter intervention (Held \& Biers, 1992) and the evaluator aspect (Jacobsen \& Hertzum, 1998) have been covered. As an increasingly important aspect of usability studies, the user profile has gained attention. By acquiring knowledge about the intended users' age and gender but also, for instance, their education and cultural background, it is considered possible to better foresee the potential difficulties that users may face when learning and interacting with the interface.

Computer-based technical devices or machines with different brands or by different manufacturers provide a possibility for consumers or buyers to choose the options that are most suitable in terms of either business profits or practical considerations in today's marketing. For instance, hospitals have to update or purchase new equipment from time to time in order to meet the requirements of treatment, and sometimes they have to consider updating and buying equipment of different brands/-types or perhaps by different manufacturers. A practical question is whether the expert users can transfer their expertise to facilitate their interacting with a new brand/type of computer-based systems- that is, if the expert users are asked to perform their familiarized or routine tasks, whether they can adapt their performance or capability to new brands/types of computer-based systems. In addition, how should designers involve users having different expertise levels in the design process, as well as choose test participants at usability evaluation stage in order to benefit the design process in an optimum way? Hence, we focus on discussing user expertise and its impact on usability evaluation in this chapter.

In the traditional rationale of usability testing, novice and experts are always given separate tests and different tasks; e.g. tests involving novice users focus on learnability while tests with expert users most often focus on optimal use (Fulkner \& Wick, 2005). The difference in testing focus cannot help but implement comparison across user levels (Faulkner and Wick, 2005). A study by researchers from the Hong Kong University of Science and Technology suggested that testing and analyzing the performance of novice users against experienced users in the same test provides an additional layer of information that testing the two separately does not provide (Goonetileke et al., 2001). Based on examination of usability test guidelines and recommendations from popular usability handbooks, such as Barnum (2002), Hackos and Redish (1998), Nielsen (1993), and Rubin (1994), the pervasive view is confirmed, i.e. testing novices and experts for different reasons and adopting different information-gathering approaches. In order to gain a picture of its full range of usability, it is essential to get data from all levels of users. Even though a number of studies argue the importance of considering users' expertise in usability tests (e.g. Goonetilleke et al., 2001; Levenson \& Tuner, 1993), few studies have systematically investigated the effect of user expertise difference on the test results when different user categories have been considered. What can be expected is that the users' level of expertise will influence the problems that 
they may face when learning how to interact, or when interacting with, a user interface, so this same aspect can be assumed to influence the results of a usability test as well.

The most recent study about user expertise issues is an empirical study examining the impact of user expertise and prototype fidelity on the outcomes of a usability test, conducted by Sauer et al. (2009). In that study, user expertise (expert vs. novice) and prototype fidelity (paper prototype, 3D mock-up, and fully operational appliance) were manipulated as independent variables in a $2 \times 3$ between-subjects design. The results revealed that experts had more usability problems but with lower severity level than novices. Prototypes with reduced fidelity were found basically suitable to predict product usability of the real products, which gives implications for prototype fidelity issues in running usability tests.

Liu (2009) analyzed and summarised the impact of user expertise on outcomes of usability tests when interacting with user interfaces of different complex levels (i.e. simple interface and complex interface). The contributions of users with different expertise (i.e. novice and expert users) during the usability tests were analyzed and compared along two dimensions, i.e. an activity dimension, referring to users' activity during task completion (e.g. actions, errors made), and a verbal explanation dimension, referring to users' verbal explanation or subjective opinions (such as their presentation of redesign proposals). The information extracted from the test results, which revealed the contributions of the users with different expertise, was classified according to these two dimensions. Both quantitative data (e.g. number of errors and task completion time); and qualitative data (e.g. cause of errors based on analysis of verbal protocols) were considered in the analysis of the users' activity, while only qualitative data (e.g. ways of presenting information, sources of decision-making for redesign proposals, contents/volume of proposals) were considered in the analysis of users' verbal explanations.

What has been identified is that a quantitative analysis of; e.g. task completion time and/or number of errors; reflects only on a fairly superficial level the differences in users' expertise. This implies; e.g. that there may be no differences between novice and expert users when interacting with a simple interface, but that the differences would be evident if interacting with a more complex interface. However, the findings concerning qualitative analysis of verbal explanation and causes of errors instead stressed the differences between novice and expert users by characterizing the basis for decisions underlying certain actions as well as the presentation of redesign proposals. Therefore, quantitative analysis is insufficient to investigate and reach an understanding of users' expertise differences and its impact on the outcome of a usability test.

Insufficiencies of domain and interaction knowledge are; e.g. consistently identified as typical causes of errors for novice users. On the other hand, the differences of information organization between previously experienced user interfaces and the interfaces interacted with in the usability tests affected expert users' task completion. Consequently, expert users made task-related errors due to terminology issues and interaction-related errors due to their 'old' mental model of how to interact with the user interface. Some errors due to a lack of attention were detected in both user groups. However, expert users made such unintended errors; due to the negative influence of expert users' contentment with their expertise level. Novice users made a few such unintended errors, due to unusual external factors (e.g. temporary and unpredictable tiredness during the tests).

The qualitative analysis of verbal statements also revealed some typical differences between novice and expert users in decision-making, presentation and judgement, which implied 
that expert users' use experience and novice users' interaction experience differ in contributing to product design and development.

\subsection{Implications for choice of test subjects}

Most researchers consider it important to understand user requirements when developing products (e.g. Cooper \& Kleinschmidt, 2000; Nielsen, 1993; Ullrich \& Eppinger, 1995; Urban \& Hauser, 1993). Users' involvement in the design process is critical for understanding user requirements for the products. Engelbrektsson (2004) pointed out that the choice of participants is a key issue for eliciting user requirements in user studies. There has been a debate between researchers regarding whether novice or expert users should be chosen for the design process. For instance, in the traditional scientific view, 'naïve' users (users without any knowledge or use experience about a certain product) are suggested to be chosen for experimental tests in order to avoid the bias of previous experiences and habits (e.g. Chapanis, 1959). However, Johnson and Baker (1974) argued that such 'naïve' users could lead to invalidity of the test results in the product development. A study made by Engelbrektsson et al. (2000) found that users with little or no prior product use experience based their assessments on interaction experiences made during the product (usability) test only, while users with long product use experience typically made references also to prior experiences in their assessments and comments on the product being tested.

In the product development process, a most common question for designers is how to choose users as test subjects when carrying out usability evaluation on a new, recently developed product/system. The key point is whether expert users can transfer their previous expertise or knowledge to facilitate their interacting with an unknown or recently developed machine/system. Engelbrektsson (2004) classified users' use experience into three categories: problem experience (e.g. experiencing problems with existing product design), interaction experience (e.g. users interact with a user interface during the development process in an experimental test setting), and product use experience (e.g. experience gained from use situations). Engelbrektsson et al. (2000) stated that expert users with long product use experience could combine their previous use experiences and their interaction experience in their assessments and comments on the new product being evaluated.

Liu (2009) analyzed the characteristics of novice and expert users' difference in terms of redesign proposals and ways of presentation during usability evaluation. The expert users' proposals appeared to be inductive in character, i.e. the expert users summarized their redesign suggestions based on long-term practical experience, while the novice users' proposals appeared to be deductive, i.e. they summarized their redesign suggestions either based on a few incidents experienced in the short-term period or based on their subjective reasoning. This implied that users' subjective comments on redesign proposals and ways of presentation are related to differences in users' expertise. Novice users may provide more useful information on design issues describing how to manipulate a simple interface (including relevant buttons and menus etc.), while expert users can provide information on more experienced users' problems when faced with a new design and can better project their interaction experience in a controlled test environment to real-use conditions. In terms of the guessability and learnability of the new interface, novice users' information originated from their interaction experience during the test only, while expert users' information originated from the combination of their interaction experience during the test and references also to prior experiences with other types or brands of products. 
Concerning important implications for choice of test subjects in usability tests, a general point is that choosing expert users as test participants may compensate for the limitations of usability tests, in that the interaction experience gained during the test can indeed be weighed against actual use, and use during different use conditions. This has, for instance, been suggested by Karlsson (1996). Liu (2009) indicated that interaction situations, i.e. complexity levels of interfaces, should also be considered when choosing test participants for usability tests. In the case of interacting with simple interfaces, novice and expert users should be involved in usability tests but for different reasons, i.e. involving novice users for investigating interaction or interface aspects, and expert users for redesign proposals. However, in the case of interacting with complex medical user interfaces, expert users are more suitable for usability tests.

At the user research stage, expert users should be involved, since expert users can benefit the research with useful and practical information based on their own previous use experience, problem experience, and collected news of other users' experience. Evaluation and conceptual design are two important stages in the iterative design process, where necessary usability evaluation is requested. At the conceptual design stage, initial concept products or prototypes are normally created. Due to business commercial and confidentiality reasons, the analytical evaluation approach by in-house engineers or usability experts is widely adopted in medical industries for verification of the conceptual design. Although medical device users should receive special medical training before starting real use of the devices, ease of learning is always a basic and critical usability heuristic for device design when considering safety and risk management in the medical health care system. By taking novice users' learning experience by exploration into consideration during the usability inspection process, analysts can successfully predict real novice users' performance and their potential problems with the design. At the evaluation stage, an empirical evaluation approach is normally to be employed on manufactured machines or devices with full functions. In order to get accurate users' elicitations, novice users should be employed in the usability evaluation as test subjects for medical devices with simple user interfaces, while expert users should be employed in the usability evaluation as test subjects for medical devices with complex user interfaces.

\section{Summary}

This chapter shows the importance of user profiles in the interface design process, and especially aims at updating the current knowledge of research about novice/expert issues and emphasizes novice and expert users' difference in various interaction situations, as well as providing key implications for interface design.

It is indicated that the effect of users' expertise on the empirical evaluation results may differ between simple and complex user interfaces. Expert users outperform novice users when interacting with a complex interface, but not when interacting with a simple interface. The analysis of redesign proposals has implied that novice and expert users differ in the content and coverage of information suggested, as well as in ways of presentation. Expert users' previous use experience can have both positive and negative influence on users' interaction with interfaces. On the one hand, previous use experience could benefit expert users through richer interaction knowledge. On the other hand, expert users appear to rely on their previous use experience and stick to their old mental models of task completion, which has a negative influence on their mental models' adaptation to the interaction with a new or 
unknown interface. Compared with novice users' proposals, expert users' proposals appeared to be more concrete and detailed in content and volume, as well as broader and deeper in coverage. Novice users proposed redesign suggestions based on their interaction experience during the test, and on deductive reasoning - while expert users proposed redesign suggestions based on their interaction experience during the test, and on inductive reasoning that referred to their prior use experience with other types or brands of products. Due to lack of experience or practice, personal preferences were found to be a basis of novice users' judgments and redesign proposals. Due to more use experience or practice, expert users appeared to be unbiased in subjective assessments.

When choosing participants for usability tests, it is necessary to consider both users' expertise difference and the level of complexity of the interface to be tested. For simple user interfaces, novice users should be involved in usability evaluation for eliciting useful information about how to manipulate the interface (e.g. menus and buttons), while expert users should be involved for eliciting constructive information on re-learning issues with a new design as well as suggesting helpful redesign proposals. For complex medical user interfaces, expert users should be more suitable to be chosen as test subjects in usability evaluation due to their constructive redesign proposals as well as the practical usability problems identified by their performance.

The differences in information organization between the previously used interfaces and a new or unknown interface interacted with in the tests; can influence expert users' interaction with the new or unknown interface. When the information organization of the previously used interfaces resembles that of the new or unknown interface, expert users can outperform novice users. When there is a big difference between the previously used interfaces and the new or unknown interface concerning information organization, expert users' old mental model or previous use experience can have negative effects on their interaction.

Although science and technology provide the possibility for the $\mathrm{HCI}$ and interface design to develop rapidly and innovatively, there still exist some challenges for designers and engineers to go deeper in thinking and studies - for instance, how to deal with innovations of interface elements (e.g. navigation methods, terminology issues, icons and their representations) so as to balance the old and new designs and to avoid confusion for users, how to understand and apply globalization and standardization in interface design, and how to reach optimal trade-offs when considering different attributes of user profiles. All these questions urge the necessity and importance of investments in research on user profiles in the near future.

\section{References}

ACM SIGCHI, 1992. Curricula for Human-computer Interaction. ACM Special Interest Group on Computer-Human Interaction Curriculum Development Group, New York.

Barret, E., and Lally, V., 1999. Gender differences in an on-line learning environment. Journal of Computer Assisted Learning, 15(1), 48-60.

Belenky, M.F., Clinchy, B.M., Goldberger, N.R., and Tarule, J.M., 1986. Women's ways of knowing. Basic Books, New York.

Botwinick, J., 1973. Aging and behaviour. Springer, New York.

Broos, A., 2005. Gender and information and communication technologies (ICT) anxiety: Male self-assurance and female hesitation. Cyber Psychology \& Behaviour, 8(1), 2131. 
Brown, D.E., 1991. Human Universals. McGraw-Hill, New York.

Burns, K., 2000. Mental models and normal errors in naturalistic decision making. Proceedings of 5th Conference on Naturalistic Decision Making, Tammsvik.

Buur, J., and Windum, J., 1994. MMI Design - Man-Machine Interface. Danish Design Centre, Copenhagen, Denmark.

Chaparro, A., Bohan, M., Fernandez, J., Choi, S.D., Kattel, B., 1999. The impact of age on computer input device use: psychophysical and physiological measures. International Journal of Industrial Ergonomics, 24, 503-513.

Chapanis, A., 1959. Research techniques in human engineering. John Hopkins University Press, Baltimore, MA.

Chi, M.T.H., Feltovich, P.J., and Glaser, R., 1981. Categorization and representation of physics problems by experts and novices. Cognitive Science, 5, 121-152.

Clemmensen, T., Hertzum, M., Hornbæk, Shi, Qx., Yammiyavar, P., 2009. Cultural cognition in usability evaluation. Interacting with computers, 21, 212-220.

Cooper, R.G., and Kleinschmidt, EmJ., 2000. New Product Performance: What distinguishes Star products, Australian Journal of Management, 25(1), 17-46.

Craik, K.J.W., 1943. The Nature of Explanation. Cambridge, U.K.: Cambridge University Press.

Craik, F.I.M., Salthouse, T.A., 2000. The Handbook of Aging and Cognition. 2nd ecition. Lawrence Erlbaum Associates Inc., New Jersey.

Czaja, S.J., Sharit, J., 1993. Age differences in the performance of computer-based work. Psychology and Aging, 8(1), 59-67.

Darin, E.R., Meitzler, T.J., Witus, G., Sohn, E., Bryk, D., Goetz, R., and Gerhart, G.R., 2000. Computational modelling of age-differences in a visually demanding driving task: vehicle detection. IEEE Transactions on Systems, Man, and Cybernetics, Part A: Systems and Humans, Vol.30, No.3., 336-346.

Davies, S.P., 1994. Knowledge restructuring and the acquisition of programming expertise. International Journal of Human-Computer Studies 40, 703-726.DiSessa, A.A. 1983. Phenomenology and the evolution of intuition. In: D. Gentner and A.L. Sevens (Eds.), Mental Models. Hillsdale, NJ: Lawrence Erlbaum Associates. 15-34.

Doane, S.M. 1986. A longitudinal study of unix users' expertise, unix mental models, and task performance. Doctoral thesis. University of California, Santa Barbara, CA, USA. Dissertation Abstracts International. 48: 585B.

Dreyfus, H.L., and Dreyfus, S.E., 1986. Mind over machine: The power of human intuition and expertise in the era of the computer. Free Press, New York.

Engelbrektsson, P., Yesil, Ö, and Karlsson, I.C.M., 2000. Eliciting customer requirements in focus group interviews: can efficiency be increased? EIASM: The 7th international product development management conference, May 29-30. 129-141

Engelbrektsson, P., 2004. Enabling the user - Exploring methodological effects on user requirements elicitation. Doctoral thesis. Chalmers University of Technology, Gothenburg, Sweden.

Faulkner, X., 2000. Usability Engineering. Palgrave, UK.

Faulkner, L., and Wick, D., 2005. Cross-user analysis: Benefits of skill level comparison in usability testing. Interacting with Computers, 17, 773-786.

Goonetilleke, R.S., Shih, H.M., Kurniawan, S.H., On, Fritsch, 2001. Effects of training and representational characteristics in icon design. International Journal of HumanComputer Studies, 55(5), 741-760. 
Greeno, J.G. 1983. Conceptual entities. In: D.Gentner and A.L. Stevens (Eds.), Mental Models, Hillsdale, NJ: Lawrence Erlbaum Associates. 227-252.

Hackman, G.S., and Biers, D.W., 1992. Team usability testing: are two heads better than one? Proceedings of the Human Factors Society 36th Annual Meeting. Santa Monica: HFS, 1205-1209.

Hackos, J.T., Redish, J.C., 1998. User and task analysis for interface design. Wiley, New York.

Hawthorn, D., 2000. Possible implications of aging for interface designers. Interacting with computers, 12, 507-528.

Hedge, A., 1998. Design of hand-operated devices. In: N.A. Stanton (Ed.), Human Factors in Consumer Products. Taylor \& Francis Ltd., UK.

Held, J.E., and Biers, D.W., 1992. Software usability testing: Do evaluator intervention and task structure make any difference? Proceedings of the Human Factors Society 36th Annual Meeting. Santa Monica: HFS, 1215-1219.

Hitchcock, D.R., Lockyer, S., Cook, S., Quigley, C., 2001. Third age usability and safety: an ergonomics contribution to design. International Journal of Human-Computer Studies, 55, 635-643.

Janhager, J., 2003. Classification of users - due to their relation to the product. Proceedings of the International Conference on Engineering Design, Stockholm, Sweden.

Janhager, J., 2005. User consideration in early stages of product development - Theories and methods. Doctoral thesis. Royal Institute of Technology, Stockholm, Sweden.

Johnson, E.M., and Baker, J.D., 1974. Field testing. The delicate compromise. Human Factors, 16, 203-214.

Johnson-Laird, P.N., 1983. Mental Models - Towards a Cognitive Science of Language, Inference and Consciousness. Cambridge MA: Harvard University Press.

Jørgensen, A.H., 1989. Using the thinking-aloud method in system development. In: G.. Salvendy and M.J. Smith (Eds.), Designing and Using Human-Computer Interfaces and Knowledge Based Systems. Amsterdam: Elsevier Science Publishers, 743-750.

Kahneman, D., and Tversky, A., 1982. The simulation heuristic. In: D. Kahneman, P. Slovic, and A. Tversky (Eds.), Judgment under Uncertainty Heuristics and Biases. Cambridge, U.K.: Cambridge University Press.

Kang, N.E., Yoon, W.C., 2008. Age- and experience-related user behavior differences in the use of complicated electronic devices. International Journal of Human-Computer Studies, 66, 425-437.

Karat, J., 1988. Software evaluation methodologies. In: M. Helander (Ed.), Handbook of Human-Computer Interaction, 891-903. Amsterdam: Elsevier.

Karat, C.M., Campbell, R., and Fiegel, T., 1992. Comparison of empirical testing and walkthrough methods in user interface evaluation. Proceedings of the ACM CHI'92 Conference. Addison-Wesley, Reading, M.A., 397-404.

Karlsson, M.A., 1996. User requirements elicitation - A framework for the study of the relation between user and artefact. Doctoral thesis. Chalmers University of Technology, Gothenburg, Sweden.

Held, J.E., and Biers, D.W., 1992. Software usability testing: Do evaluator intervention and task structure make any difference? Proceedings of the Human Factors Society 36th Annual Meeting. Santa Monica: HFS, 1215-1219.

Jacobsen, N.E., and Hertzum, M., 1998. The evaluator effect in usability studies: problem detection and severity judgments. Proceedings of the Human Factors and Ergonomics Society 42nd Annual Meeting. Santa Monica, CA: HFES, 1336-1340. 
Klein, G., 1999. Sources of power: How people make decisions. MIT Press, London.

Kuniavsky, M., 2003. Observing the User Experience: A Practitioner's Guide to User Research. San Francisco: Morgan Kaufmann.

Kurniawan, S., 2008. Older people and mobile phones: A multi-method investigation. International Journal of Human-Computer Studies, 66, 889-901.

Laberge, J.C., Scialfa, C.T., 2005. Predictors of web navigation performance in a life span sample of adults. Human Factors, 47(2), 289-302.

Landauer, T.K., 1988. Research methods in Human-Computer Interaction. In: M. Helander (Ed.), Handbook of Human-Computer Interaction. 905-928. Amsterdam: Elsevier.

Larkin, J.H., 1983. The role of problem representation in physics. In: D. Gentner and A.L. Stevens (Eds.), Mental Models. Hillsdale, NJ: Erlbaum, 75-98.

Liu, Y., Osvalder, A-L., Karlsson, M., 2007. User's expertise differences when interacting with simple medical interfaces. Lecture Notes in Computer Science 4799, Springer, 441-446, ISBN 978-3-540-76804-3.

Liu, Y., 2009. Usability Evaluation of Medical Technology - Investigating the effect of user background and users' expertise. Doctoral thesis. Chalmers University of Technology, Gothenburg, Sweden.

Liu, Y., and Osvalder, A-L., 2009. Usability Tests as a Benchmarking Tool - A Case Study on Complex Medical Ventilators. Contemporary Ergonomics, 182-188.

McClelland, I., 1995. Product assessment and user trials. In: Wilson, J.R., Corlett, E.N. (Eds.), Evaluation of Human Work. Taylor \& Francis Ltd., London.

Monö, R., 1974. Analys och värdering av designfunktioner. Sveriges Mekaniksförbund.

Nielsen, J., 1993. Usability engineering. San Francisco: Morgan Kaufmann.

Nisbett, R.E., Peng, K.P., Choi, I., Norenzayan, A., 2001. Culture and systems of thought: holistic versus analytic cognition. Psychological Review 108 (2), 291-310.

Nisbett, R.E., 2003. The geography of thought: How Asians and Westerners think differently - and Why. Brealey, London.

Norman, D. A., 1983. Some observations on mental models. In: D. Gentner and A.L., Stevens (Eds.), Mental models. Hillsdale, NJ: Lawrence Erlbaum Assoc.

Norman, D. A., and Draper, S. W., 1986. User centered system design: New perspectives on human-computer interaction. Hillsdale, NJ: Lawrence Erlbaum Associates.

Okun, M.A., and Di Vesta, F.J., 1976. Cautiousness in adulthood as a function of age and instructions. Journal of Gerontology, 31(5), 571-576.

Osvalder, A-L., and Ulfvengren, P., 2009. Human-technology systems. In Bhgard, G et al. (Eds.) Work and technology on human terms, Prevent, Sweden.

Osvalder, A-L., Rose, L., and Karlsson, S., 2009. Methods. In Bhgard, G et al. (Eds.) Work and technology on human terms, Prevent, Sweden.

Owsley, C., Ball, K., Sloane, M.E., Roenker, D.L., and Bruni, J.R., 1991. Visual/cognitive correlates of vehicle accidents in older drivers. Psychology and Aging, 6(3), 403415.

Oxford Advanced Learner's Dictionary, 1995. Oxford University Press; 5th edition, UK.

Philbin, M., Meier, E., Huffman, S., and Boverie, P., 1995. A survey of gender and learning styles. Sex Roles, 32(7/8), 485-494.

Pinker, S., 2006. The blank slate. The general psychologist, 41(1), 1-8.

Preece, J., 2002. Interaction Design - beyond human-computer interaction. John Wiley \& Sons, Inc., USA. 
Reason, J., 1990. Human Error. Cambridge, UK: Cambridge University Press.

Rogers, Y., Rutherford, A., and Bibby, P., 1992. Models in the Mind - Theory, Perspective, and Application. London: Academic Press.

Rubin, J., 1994. Handbook of Usability Testing: How to plan, design, and conduct effective tests. Wiley, New York.

Sadler-Smith, E., 1999. Intuition-analysis style and approaches to studying. Educational Studies, 25(2), 159.

Sasse, M.A., 1997. Eliciting and describing users' models of computer systems. School of Computer Science, Birmingham, University of Birmingham.

Sauer, J., Seibel, K., and Bruno Rüttinger, B., 2009. The influence of user expertise and prototype fidelity in usability tests. Applied Ergonomics, 41(1), 130-140.

Schneiderman, B., 2000. Universal usability. Communication. ACM 43(5), 85-91.

Shneiderman, B., 1992. Designing the user interface: Strategies for effective humancomputer interaction. 2nd edition. Reading, MA: Addison-Wesley.

Scialfa, C., Ho, G., Laberge, J., 2004. Perceptual aspects of gerotechnology. In: Burdick, D.C. Kwon, S. (Eds.), Gerotechnology. Springer Publishing Company, New York, 18-41.

Segall, M.H., Dasen, P.R., Berry, J.W., Poortinga, Y.H., 1999. Human behaviour in global perspective: An introduction to cross-cultural psychology, 2nd edition. Simon \& Schuster, M.A.

Smith, M.W., Sharit, J., Czaja, S.J., 1999. Aging, motor control, and the performance of computer mouse tasks. Human Factors, 41(3), 389-396.

Spiro, R.J., Coulson, R.L., Feltovich, P.J., and Anderson, D.K., 1988. Cognitive flexibility theory: advanced knowledge acquisition in ill-structure domains. In: Proceedings of the 10th Annual Conference of the Cognitive Science Society. Hillsdale, NJ: Lawrence Erlbaum Associates. 375-383.

Spiro, R.J., Feltovich, P.J., Jacobson, M.J., and Coulson, R.L., 1991. Cognitive flexibility, constructivism and hypertext: random access instruction for advanced knowledge acquisition in ill-structured domains. Educational Technology 31, 24-33.

Ullrich, K.T., and Eppinger, D.E., 1995. Product Design and Development, McGraw-Hill Inc., Singapore. ISBN 0-07-113742-4.

Urban, G.L., and Hauser, J.R., 1993. Design and marketing of new products, Prentice-Hall Inc., N.J. ISBN 0-13-201567-6.

Vicente, K.J., and Wang, J.H., 1998. An ecological theory of expertise effects in memory recall. Psychological Review, 105, 33-57.

Virzi, R.A., 1992. Refining the test phase of usability evaluation: How many subjects is enough? Human Factors, 34(4), 457-468.

Warell, A., 2001. Design syntactics: A functional approach to visual product form - Theory, models, and methods. Doctoral thesis. Chalmers University of Technology, Gothenburg, Sweden.

Webster's Third New International Dictionary, 1976. Springfield, MA: Merriam

Welford, A.T., 1977. Motor performance, In: Birren, J.E., Schaie, K.W. (Eds.), Handbook of the psychology of aging. Van Nostrand Reinhold Co., New York.

Ziefle, M., Bay, S., 2005. How older adults meet complexity: aging effects on the usability of different mobile phones. Behaviour and Information Technology, 24(5), 375-389. 


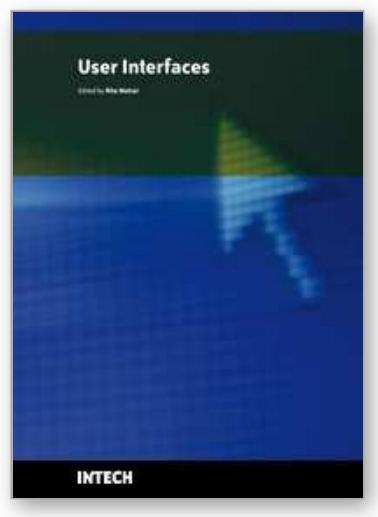

\author{
User Interfaces \\ Edited by Rita Matrai
}

ISBN 978-953-307-084-1

Hard cover, 270 pages

Publisher InTech

Published online 01, May, 2010

Published in print edition May, 2010

Designing user interfaces nowadays is indispensably important. A well-designed user interface promotes users to complete their everyday tasks in a great extent, particularly users with special needs. Numerous guidelines have already been developed for designing user interfaces but because of the technical development, new challenges appear continuously, various ways of information seeking, publication and transmit evolve. Computers and mobile devices have roles in all walks of life such as in a simple search of the web, or using professional applications or in distance communication between hearing impaired people. It is important that users can apply the interface easily and the technical parts do not distract their attention from their work. Proper design of user interface can prevent users from several inconveniences, for which this book is a great help.

\title{
How to reference
}

In order to correctly reference this scholarly work, feel free to copy and paste the following:

Yuanhua Liu, Anna-Lisa Osvalder and MariAnne Karlsson (2010). Considering the Importance of User Profiles in Interface Design, User Interfaces, Rita Matrai (Ed.), ISBN: 978-953-307-084-1, InTech, Available from: http://www.intechopen.com/books/user-interfaces/considering-the-importance-of-user-profiles-in-interfacedesign

\section{INTECH}

open science | open minds

\author{
InTech Europe \\ University Campus STeP Ri \\ Slavka Krautzeka 83/A \\ 51000 Rijeka, Croatia \\ Phone: +385 (51) 770447 \\ Fax: +385 (51) 686166 \\ www.intechopen.com
}

\author{
InTech China \\ Unit 405, Office Block, Hotel Equatorial Shanghai \\ No.65, Yan An Road (West), Shanghai, 200040, China \\ 中国上海市延安西路65号上海国际贵都大饭店办公楼 405 单元 \\ Phone: +86-21-62489820 \\ Fax: +86-21-62489821
}


(C) 2010 The Author(s). Licensee IntechOpen. This chapter is distributed under the terms of the Creative Commons Attribution-NonCommercialShareAlike-3.0 License, which permits use, distribution and reproduction for non-commercial purposes, provided the original is properly cited and derivative works building on this content are distributed under the same license. 